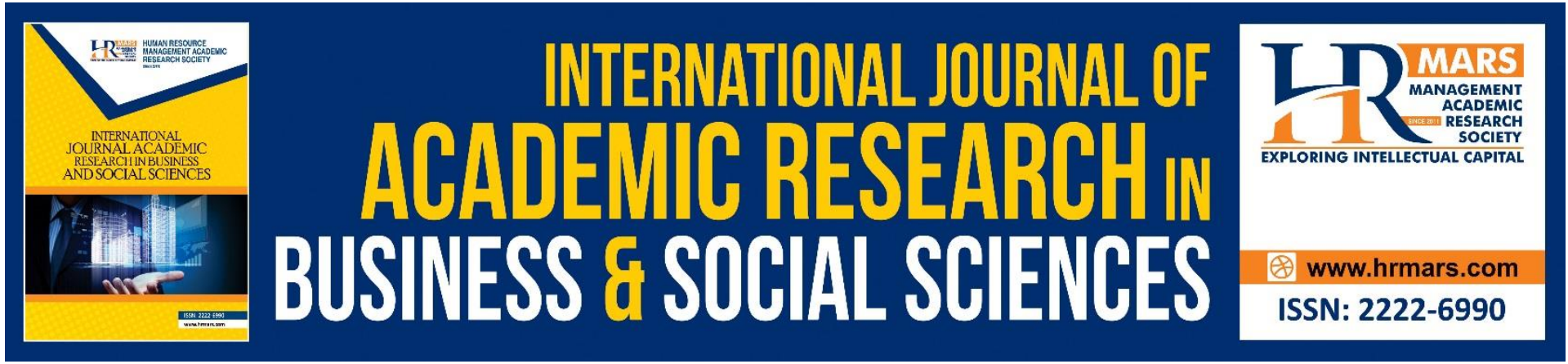

\title{
Coping Mechanism, Psychological Distress and Counselling Acceptance among Victims of Domestic Violence in Malaysia
}

Deborah Priya Hermangild, Asmah Ismail, Wan Marzuki Jaafar, Caryn Mei Hsien Chan

To Link this Article: http://dx.doi.org/10.6007/IJARBSS/v11-i8/10659

DOI:10.6007/IJARBSS/v11-i8/10659

Received: 18 June 2021, Revised: 21 July 2021, Accepted: 12 August 2021

Published Online: 26 August 2021

In-Text Citation: (Hermangild et al., 2021)

To Cite this Article: Hermangild, D. P., Ismail, A., Jaafar, W. M., \& Chan, C. M. H. (2021). Coping Mechanism, Psychological Distress and Counselling Acceptance among Victims of Domestic Violence in Malaysia. International Journal of Academic Research in Business and Social Sciences, 11(8), 1550-1567.

Copyright: (c) 2021 The Author(s)

Published by Human Resource Management Academic Research Society (www.hrmars.com) This article is published under the Creative Commons Attribution (CC BY 4.0) license. Anyone may reproduce, distribute, translate and create derivative works of this article (for both commercial and non-commercial purposes), subject to full attribution to the original publication and authors. The full terms of this license may be seen at: http://creativecommons.org/licences/by/4.0/legalcode

Vol. 11, No. 8, 2021, Pg. 1550 - 1567

Full Terms \& Conditions of access and use can be found at http://hrmars.com/index.php/pages/detail/publication-ethics 


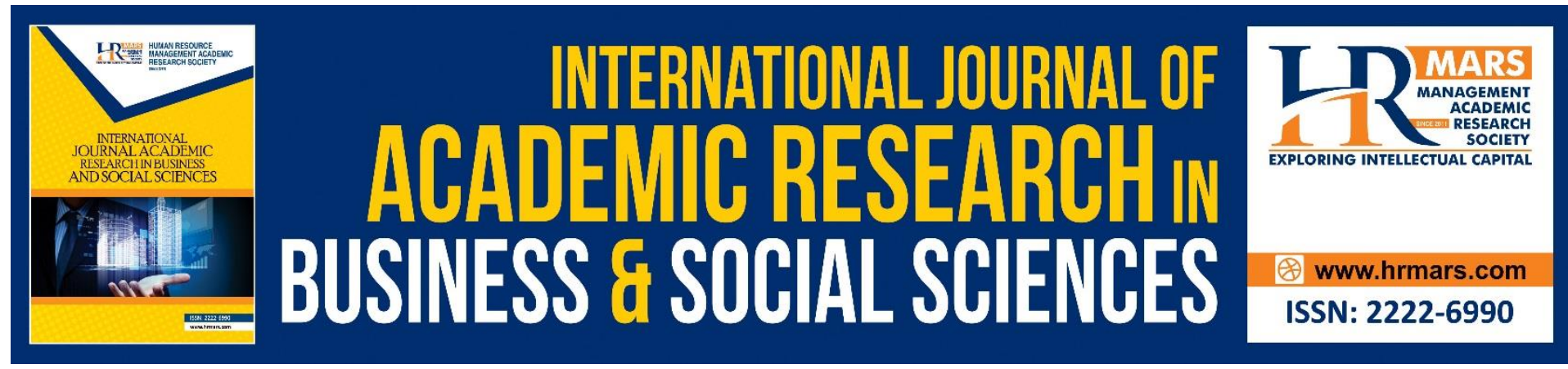

\title{
Coping Mechanism, Psychological Distress and Counselling Acceptance among Victims of Domestic Violence in Malaysia
}

\author{
Deborah Priya Hermangild ${ }^{1}$, Asmah Ismail ${ }^{1}$, Wan Marzuki \\ Jaafar $^{1}$, Caryn Mei Hsien Chan ${ }^{2}$ \\ ${ }^{1}$ Department of Counselor Education and Counseling Psychology, Faculty of Educational \\ Studies, Universiti Putra Malaysia, 43400, Serdang, Selangor, Malaysia 43400 Serdang, \\ Malaysia, ${ }^{2}$ Faculty of Health Sciences, Universiti Kebangsaan Malaysia, 43600 Bangi, \\ Selangor, Malaysia \\ Email: asmahis@upm.edu.my
}

\begin{abstract}
Domestic violence is a worldwide problem that is unaffected by race, age, culture, or gender. It charges have been on the rise in Malaysia in recent years. Thus this study was conducted to examine the inherent differences in coping mechanism and psychological distress among victims of domestic violence by counselling acceptance. A quasi-experimental design involving measures at baseline and three months follow-up was used. All domestic violence victims ( $N$ = 58) between September 2018 to March 2019 were recruited from a government funded victim care centre. Three Bahasa Malaysia translated versions of instruments were used: Beck Depression Inventory, Beck Anxiety Inventory and Brief Coping Orientation to Problems Experienced. Findings showed no significant differences between domestic violence victims who accepted counselling vs those who did not in terms of sociodemographic factors except for duration of abuse. Counselling acceptance rates were minimal as only $50 \%$ of participants accepted counselling. Both groups favoured approach coping mechanism ( $n=41,70.69 \%$ ) compared to avoidant coping mechanism ( $n=10,17.24 \%)$. There was a significant reduction in symptoms of depression (BDI: $r=0.82, p<.05$ ) and anxiety (BAI: $r=0.71, p<.05$ ) for both groups when levels were examined at 3 months follow-up. There is a need to examine ways to increase counselling acceptance rates among victims of domestic violence. Overall, this study offers insight into counselling acceptance rates and its psychological correlates among domestic violence victims at a single centre.
\end{abstract}

Keywords: Coping Mechanism, Counselling, Domestic Violence, Psychological Distress

\section{Introduction}

Domestic violence is present in almost every society in this world and affects people from all walks of life. The current trend shows an increase in the number of domestic violence cases in Malaysia. In Malaysia, a study was conducted by Othman et al. (2019) showed a 22\% prevalence of domestic violence among women attending urban primary care clinics. According to the statistics from the Royal Malaysia Police, in 2010 there were 3173 cases, 
while in 2013 there were 4123 cases and it increased to 5014 cases in 2015 and then to 5421 cases in 2018 (WAO, 2017). Approximately 9\% of married/ partnered women in Peninsular Malaysia have been a victim of domestic violence at some point in their life (WAO, 2017). Thus, it is important to look into the psychological well-being and welfare of these women (National Report on Violence and Health Malaysia, 2006, as cited by Ghani, 2018). Women play a very important role in a family, society and serve as role models to their children. Domestic violence can be a cycle that continues to the next generation (Ghani, 2018). Therefore, to break the cycle, it is important to address the psychological well-being of the victim from the very beginning to prevent it from further damage.

Tackling domestic violence in Malaysia poses significant challenges due to some barriers faced by women in bringing their abuse partners to justice. The main barrier strongly relates to the victim's cultural values and beliefs (Rahman et al., 2019). According to Brabek and Guzman (2008), many stereotypes and criticisms by society also play a role in whether the women decide to take actions with regards to their abuse. Women who do leave abusive relationships are often stigmatized (Brabeck \& Guzman, 2008). These sorts of beliefs affect their decision to hide their abuse from others. At the same time, the feelings of shame and self-blame combined with financial dependency on the abuser make the problem worse (Rahman et al., 2019).

According to Ling (2013), domestic violence victims do not seek counselling or hesitate to do so even when they face anxiety or depression due to their circumstances. Some victims may be living too far away to get treatment or may have no transportation to go to the centres that provide counselling services including the Victim Care Centre even if such services are offered at no cost. Ling (2013) further elaborates that there are also those who gave up on seeking help and outside intervention as they felt it would not render them the justice they needed. However, if the victims do not accept counselling or get treatment, are they coping well on their own and what is the coping mechanism that they utilise? Sociodemographic factors such as the victim's age, race, education, income level, number of children and duration of abuse may play a role in whether the victim accepts counselling or does not accept counselling and also how the victim copes with the psychological distress that they experience (WHO, 2021).

In Malaysia, domestic violence women victims still choose to suffer in silence due to the belief that anything that happens at home within the family should remain there (WAO, 2011). According to Ghani (2018), key issues relating to the nature, causes, and outcomes of abusive behaviour at home are still under-explored in Malaysia. It is believed that the findings from such studies are the key components in proposing any reasonable solutions to deal with this issue.

This study of victimology aimed to examine the difference in the severity of psychological distress among those who accepted counselling compared to those who did not accept counselling as well as what coping mechanism works best for them. Guidance and counselling for the victims as well as those who are at risk could help reduce the prevalence of domestic violence. This study attempted to provide some insight to understand the level of psychological distress among Malaysian domestic violence victims, by identifying their sociodemographic factors, coping mechanism and attitude towards counselling acceptance. Help seeking behaviour may refer to all kinds of help the victims have sought to alleviate their situation including the acceptance of counselling. Some of the other help seeking behaviours may include talking to friends and family members, making a police report, seeking a 
temporary shelter, etc. However, for the current study, help seeking behaviour was focused on whether the victim accepted counselling or did not accept counselling.

In Malaysia, results of the study conducted by Oon et al. (2016) showed help seeking behaviour for 234 participants, that about 83\% (194) of the domestic violence victims attempted to seek help from individuals outside of their marriages and from the authorities which indicate the important role of friends and family members in providing support and help for the victims.

\section{Literature Review}

For this study, two theories are used to generate a framework. The first theory is the Theory of Learned Helplessness (Overmier \& Seligman, 1967) and the second theory that underlies this study is the Cycle of Violence Theory (Walker, 1979).

\section{Theory of Learned Helplessness}

One of the theories that often arise in domestic violence is the Theory of Learned Helplessness (Overmier \& Seligman, 1967) that originated by Martin Seligman. Corbin and Gonzales (2010) describe it as an experience of being in a helpless and powerless situation that developed over time due to constant to repetitive abuse and numerous failed attempts to escape the abuse, which then leads to a poor self-esteem and psychological distress in the abused woman. Learned helplessness is a phenomenon that can be observed in humans and animals whereby they are conditioned to expect pain and suffering and eventually become immune to it and don't even try to get themselves out of that painful situation even when there is the opportunity to do so. Learned helplessness is a psychological trait, which, theoretically, results from repeated exposure to uncontrollable and aversive events (Seligman, 1975).

Western psychology expert Lenore Walker (1979) studied the behaviour of women who stay in violent relationships in attempt to explain the psychological problems of women who become victims of this domestic violence through this Theory of Learned Helplessness. Between signs of depression of being pessimistic, no motivation, low self-esteem, self-blame and self-harm, Walker holds the belief that women who have repeatedly been chastened and abused have a distortion in their cognitive thinking or problems, negative behaviour and other symptoms that are found to apply to those with depression problems. They think that whatever they do, they will not succeed until eventually they give up and have no more motivation to try to escape and allow themselves be hurt. Walker hypothesized that women stay in abusive relationships because constant abuse strips them of the will to leave. Among domestic violence victims, especially those who have been victims of repeated violence, they eventually tend to get immune to the cycle of violence and allow themselves to continue to be in that situation because they see it as something that is unavoidable and they have no other choice.

\section{Cycle of Violence Theory}

The Cycle of Violence Theory is a theoretical model developed by Walker (1979) used to describe a pattern of behaviour between the perpetrator and the victim which was based on the Theory of Learned Helplessness. Walker (1979) described women's responses to domestic abuse as 'Battered Women Syndrome', which described a psychological state of 'learned helplessness in which, following prolonged abuse, women become convinced that their efforts to stop or escape the abuse are futile so cease trying and consequently become passive (Irving \& Liu, 2020). The Cycle of Violence Theory (Walker, 1979) explains patterns of 
behaviour in an abusive, violent and unhealthy relationship. Victims of domestic violence often stay in an abusive marriage due to various factors which includes a sense of dependency on the abuser or fear of being further violated if they leave the abusive partner. Thus, they tend to remain in an abusive cycle.

According to Walker (1979), there are three phases in this cycle of violence which are, the tension-building phase, the crisis phase and the honeymoon phase. During the tensionbuilding phase, the perpetrators or husband will attack their spouses with abusive words and make accusations of their spouse as the result of minor offenses by the woman. At this time the woman who is a victim would be passive, in fear, silenced, try not to trigger the rage of predators. During the crisis phase, stress and tension peak to the maximum level and then ends with violence. It usually occurs as a result of external problems, past problems or emotional problems of the husband itself and sometimes there is no direct connection with the woman. At this point physical abuse, sexual abuse or even murder can occur.

Finally, in the honeymoon phase, after a violent episode, the couple returns to this phase. Her husband becomes remorseful, seeks forgiveness, becomes very caring and promises not to do it again in the future. This woman becomes guilt stricken if she chooses to leave the family and feels that she is accountable as a wife to care for the welfare of her husband and children. However, based on the number of recurrence cases, it shows that the abuse usually reoccurs again after some time. Those phases are shown in the model of the Cycle of Violence Theory in Figure 1.

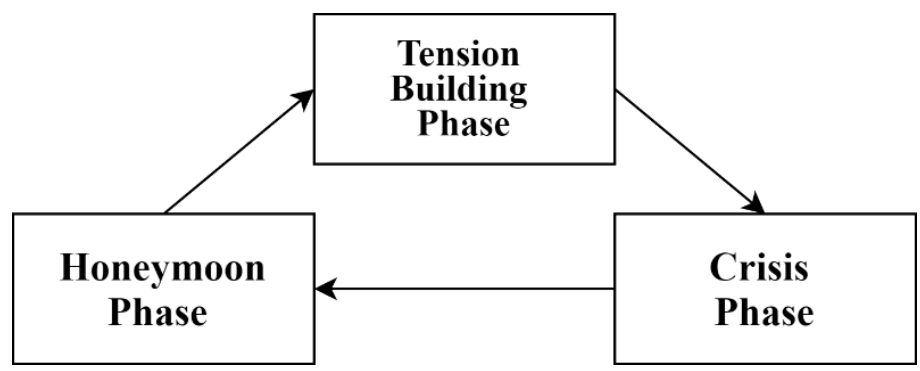

Figure 1: Cycle of Violence Theory.

Note. The three phases of the Cycle of Violence Theory. Adapted from The Battered Woman (p. 55), by Walker, L. (1979) Harper and Row.

The principles of the Cycle of Violence Theory (Walker, 1979) which are of interest to this study are i) understanding why domestic violence victims choose to remain in an abusive relationship (e.g. due to sociodemographic factors) ii) how can they break the cycle iii) what's the risk of the cycle happening again. Through this study, Cycle of Violence Theory can explain why some women choose to remain in an abusive relationship and also how this study can help design a treatment plan that can help victims to empower themselves and to free themselves from this destructive cycle of helplessness.

\section{Materials and Methods}

\section{Research design}

The main research design that this study employed was a quantitative research method using a quasi-experimental design to assess the hypothesized interaction of the intervention provided to the victims who agreed to accept counseling in regards to their level of psychological distress.

The study uses the quasi-experimental approach with a non-equivalent control group pre-and post-test study design. It is a between-subjects design whereby the treatment group is given 
a pre-test, receives counseling, and then given a post-test while another group, known as the non-equivalent control is given the pre-test and post-test but no counseling is provided.

To achieve the aim of the study, two objectives were formulated as below:

1. To describe the sociodemographic factors, coping mechanisms counseling acceptance, and psychological distress among the victims of domestic violence.

2. To explore the differences in sociodemographic factors, coping mechanisms and psychological distress among domestic violence victims who accepted counseling and those who did not accept counseling at baseline and three months follow-up.

The study aimed to identify the following hypotheses:

1. There is a significant difference in sociodemographic factors between domestic violence victims who accepted counseling and those who did not accept counseling.

2. There is a significant difference in coping mechanisms between domestic violence victims who accepted counseling and those who did not accept counseling at three months follow-up.

3. There is a significant difference in psychological distress between domestic violence victims who accepted counseling and those who did not accept counseling at three months follow-up.

\section{Study Setting}

This study was conducted at a state-funded counseling and psychological services center focused on victim care in Malaysia which offers support to domestic violence victims once they lodge a police report. It was mainly established under the Criminal Investigation Department of the Royal Malaysian Police to help victims of crimes including domestic violence victims by providing counseling and professional psychological services. The counseling sessions are conducted by Victim Care Officers who are qualified civilian staff hired within the police department under the Malaysian Civil Service Department. Victim Care Officers consist of both psychology and counseling majors who have been trained to provide psychological and counseling services to the victims of crime. They are supervised by a senior Victim Care Officer who is based in the Bukit Aman main police headquarters in Kuala Lumpur, Malaysia. All Victim Care Officers undergo continuous professional development training and are supervised to ensure the quality and efficacy of the counseling and psychological services provided to the clients. Victim Care Officers are specialized in skills and knowledge in dealing with victims of crime and those experiencing psychological distress due to violence and abuse For this study, the focus was given to victims who lodged a police report within Negeri Sembilan and were contacted by the Victim Care Officer in Negeri Sembilan to be offered free counseling services at the Negeri Sembilan Victim Care Centre because the present study was conducted in that location. The usual procedure at the Victim Care Centre involves the victims who made a police report would be contacted by the Victim Care Officer and offered counseling or psychological intervention to help them cope with any possible psychological distress that they may be experiencing. This service is purely voluntary. The victim can choose to accept counseling intervention and decide later whether to continue or terminate the intervention. Based on previous records, some of the reasons given for termination include transportation issues, distance from home or workplace, and conflict with work schedule. Victims sometimes seek help immediately after the abuse while some of them choose to 
come in later when it is more convenient. Due to the timeline difference in accepting counseling, the recovery rate also varies for each individual.

\section{Population and Sampling Procedure}

The population of this study was all the domestic violence victims who lodged a police report on domestic abuse which took place in Negeri Sembilan between September 2018 till March 2019. The initial timeline assigned for data collection was September 2018 till November 2018 but due to reluctance to participate, thus the timeline was extended till March 2019 to allow for a higher rate of data collection. The data collection was chosen within that timeline because the researcher estimated that the entire data collection would take approximately ten months since there was also a follow-up post-test that was given to the participants three months after their first pre-test was given. In other words, the participants who were contacted in March were contacted again three months later which was in June or July. The three months cut-off timeline was selected because symptoms of post-traumatic stress disorder that include stress, anxiety, and psychological disorders can start to manifest three months after a stressful event (National Institute of Mental Health, 2020).

The participants of the study included victims from eight districts within Negeri Sembilan which are Seremban, Tampin, Rembau, Port Dickson, Jelebu, Jempol, Kuala Pilah, and Nilai. From September 2018 to March 2019, there were a total of 58 reports lodged by domestic violence victims that fulfilled the inclusion and exclusion criteria. The inclusion criteria were females who have been victims of domestic violence who made an official police report and residing in Negeri Sembilan. They should be either married or divorced and willing to participate in this study for at least three months. However, those who were unable to communicate (speak and write) in either Bahasa Melayu or English were excluded from the study.

The recruitment of the participants in this study was based on a non-probability sampling method using convenience sampling because the researcher selected the sample based on all cases reported and referred to the Victim Care Centre which led to a total of 58 participants that took part in this study. The researcher included the population as the subjects in the study because of its small number.

According to Crossman (2020), a population can be selected as the sample if the target group is small and is distinguished by particular traits. In this study, this group was distinguished from other domestic violence victims because they made a police report after the abuse compared to those who did not make a police report. In general, according to Fraenkel et al. (2012), convenience sampling may not be entirely generalizable to a bigger population but in some cases, when the researcher is left with no other options, this sampling method can be used but should include essential information such as the demographics and characteristics of the group.

\section{Instrumentation}

The study used three instruments, The Beck Depression Inventory (BDI), Beck Anxiety Inventory (BAI), and The Brief Coping Orientation to Problems Experienced (COPE). The BDI (Beck, Ward, Mendelson, Mock \& Erbaugh, 1961) was developed by Beck et al. in 1961 and underwent a few revisions which were then also translated to various languages. It is a 21item; self-report rating inventory that was created to measure affective, cognitive, somatic, and vegetative symptoms (e.g. weight loss, insomnia, and fatigue) which reflects the DSM-5 
characteristic and symptoms of major depression (Koku, 2016). Participants were asked to respond based on how they felt during the past week.

The BAl (Beck et al., 1988) was created by Aaron T. Beck, MD, and colleagues is a 2l-item selfreport inventory created to measure the severity of anxiety among adolescents and adults. The items in the BAI describe the emotional, physiological, and cognitive symptoms of anxiety and not depression, thus it can differentiate between anxiety and depression.

The COPE inventory was created by Carver (1989) aimed to assess the different coping strategies people use in response to stress. It is a multi-dimensional inventory with two main components which are problem-focused coping and emotion-focused coping. However, one of its challenges was that it was too lengthy, thus the Brief COPE Inventory was adapted by Carver (1997) as a shortened version of the Cope Inventory.

\section{Data Analysis}

For this study, both descriptive and inferential data analyses were carried out. The quantitative data were analyzed using the SPSS version 26 for descriptive and inferential outcomes. Descriptive statistical analysis was performed to obtain the percentage, frequencies, means, and standard deviations of the variables which are the sociodemographic factors, coping mechanism, counseling acceptance, and psychological distress.

The current study aimed to investigate the association between the independent variables and dependent variables among domestic violence victims including an exploration if there was a significant association between the sociodemographic factors, coping mechanism, counseling acceptance, and the victim's psychological distress based on the research objectives. Inferential statistics were conducted to infer the data collected from the respondents to answer the research questions of the study using the paired t-test and Pearson's Chi-Square and repeated measures Analysis of Covariance (ANCOVA).

A paired t-test was used to compare the psychological distress levels at baseline and followup for the same group of respondents. This explored if there was any significant difference in psychological distress for the group that accepted counseling and also for the group that did not accept counseling.

Psychological distress was derived from a combination of BDI and BAI scores. Respondents who scored on the threshold of 14 and above for the BDI and those who scored above the cut-off of 8 for the BAl were combined to form a new computing variable indicating 'psychological distress' (combination of depression and anxiety scores) for both the pre-and post-time points. The new variable (psychological distress) was computed by collating BDI and BAI significant cut-off scores only and was dichotomously coded as non-psychologically distressed/ psychologically distressed.

A Pearson Chi-Square was utilized to determine if there was any significant association between the categorical variables under investigation. However, there is no certainty to determine which variable influenced the other variable or vice versa. It is only describing the degree to which the quantitative variables are related without any manipulation of the variables.

Repeated Measure ANCOVA was run to test the main and interaction effects of categorical variables on a continuous dependent variable. When using ANCOVA, to test for sphericity, Mauchly's test should be assumed ( $p>.05)$, however, if it is not assumed $(p<.05)$, then an alternative measure should be used. According to Bathke et al. (2009), Greenhouse-Geiser has been the standard alternative tool of measurement that is used in various fields of study including psychology and social sciences. 


\section{Results}

Objective 1: To describe the sociodemographic factors, coping mechanisms, counseling acceptance, and psychological distress among the victims of domestic violence.

\section{Respondent's Sociodemographic Characteristics}

Table 1: Frequency Distribution of Respondents Sociodemographic Characteristics by Counselling Acceptance

\begin{tabular}{|c|c|c|c|c|c|}
\hline \multirow[t]{2}{*}{ Characteristics } & \multicolumn{2}{|c|}{$\begin{array}{l}\text { Accepted Counselling } \\
\quad(n=29)\end{array}$} & \multicolumn{2}{|c|}{$\begin{array}{l}\text { Did Not } \\
\text { Counselling } \\
(n=29)\end{array}$} & \multirow[t]{2}{*}{$\begin{array}{l}\text { Total } \\
(\mathrm{N}=58)\end{array}$} \\
\hline & Frequency & $\begin{array}{l}\text { Percentage } \\
(\%)\end{array}$ & Frequency & $\begin{array}{l}\text { Percentage } \\
(\%)\end{array}$ & \\
\hline \multicolumn{6}{|l|}{ Age } \\
\hline $17-35$ & 19 & 65.5 & 15 & 51.7 & 34 \\
\hline $36-59$ & 10 & 34.5 & 14 & 48.3 & 24 \\
\hline \multicolumn{6}{|l|}{ Income } \\
\hline $0-2000$ & 25 & 86.2 & 22 & 75.9 & 29 \\
\hline $2001-4000$ & 4 & 13.8 & 7 & 24.1 & 29 \\
\hline \multicolumn{6}{|l|}{$\begin{array}{l}\text { Number of } \\
\text { Children }\end{array}$} \\
\hline $0-3$ & 27 & 93.1 & 23 & 79.3 & 29 \\
\hline $4-7$ & 2 & 6.9 & 6 & 20.7 & 29 \\
\hline Race & 14 & 24 & 15 & 26 & 29 \\
\hline Malay & 13 & 22 & 8 & 14 & 21 \\
\hline $\begin{array}{l}\text { Indian } \\
\text { Chinese }\end{array}$ & 2 & 3 & 6 & 10 & 8 \\
\hline \multicolumn{6}{|l|}{ Education } \\
\hline $\begin{array}{l}\text { SPM \& } \\
\text { Below }\end{array}$ & 18 & 31 & 21 & 54 & 39 \\
\hline Diploma & 8 & 14 & 5 & 24 & 13 \\
\hline Degree & 3 & 5 & 3 & 9 & 6 \\
\hline \multicolumn{6}{|l|}{$\begin{array}{l}\text { Duration of } \\
\text { Abuse(Years) }\end{array}$} \\
\hline $1-5$ & 17 & 58.62 & 17 & 58.62 & 24 \\
\hline $6-10$ & 5 & 17.24 & 9 & 31.03 & 14 \\
\hline $11-15$ & 4 & 13.79 & 3 & 10.35 & 7 \\
\hline $16-20$ & 2 & 6.90 & 0 & 0 & 2 \\
\hline $21-25$ & 1 & 3.45 & 0 & 0 & 1 \\
\hline
\end{tabular}


Table 2: Frequency distribution of respondent coping mechanism by counseling acceptance

\begin{tabular}{lllll}
\hline $\begin{array}{l}\text { Coping } \\
\text { Mechanism }\end{array}$ & \multicolumn{2}{l}{ Accepted Counselling } & \multicolumn{2}{l}{ Did Not Accept Counselling } \\
\hline & Frequency & Percentage & Frequency & Percentage \\
\cline { 2 - 5 } Approach & 22 & 75.86 & 19 & 65.52 \\
Avoidant & 5 & 17.24 & 5 & 17.24 \\
Neither & 2 & 6.90 & 5 & 17.24 \\
\hline
\end{tabular}

In terms of describing the two groups, the results show that there were no significant differences in terms of their sociodemographic factors except for the duration of abuse. As for the coping mechanisms both groups favored the utilization of the approach coping style.

Objective 2: To explore the differences in sociodemographic factors, coping mechanisms, and psychological distress among domestic violence victims who accepted counseling and those who did not accept counseling at baseline and three months follow-up.

Repeated Measure ANCOVA was run to test the main and interaction effects of categorical variables on a continuous dependent variable as shown in Table 3.

Table 3: Psychological Distress, Sociodemographic Factors, Counselling Acceptance and Coping Style $(\mathrm{N}=58)$

\begin{tabular}{lllllll}
\hline Effect & $\begin{array}{l}\text { Wilks' } \\
\text { Lambda }\end{array}$ & $\boldsymbol{F}$ & Hyp. df & Error df & Sig. & Eta Squared \\
\hline PD & .82 & 3.23 & 3 & 45 & 0.031 & 0.18 \\
PD $\times$ Age & .89 & .50 & 3 & 45 & 0.686 & 0.03 \\
PD $\times$ Income & .91 & 1.50 & 3 & 45 & 0.228 & 0.09 \\
PD $\times$ Children & .98 & .24 & 3 & 45 & 0.868 & 0.02 \\
PD $\times$ Race & .86 & 2.53 & 3 & 45 & 0.069 & 0.14 \\
PD $\times$ Education & .95 & .86 & 3 & 45 & 0.467 & 0.05 \\
PD $\times$ CA & .99 & .14 & 3 & 45 & 0.933 & 0.01 \\
PD $\times$ CS & .94 & .48 & 6 & 90 & 0.823 & 0.03 \\
PD $\times$ CA $\times$ CS & .97 & .92 & 6 & 90 & 0.487 & 0.06 \\
PD & .82 & 3.228 & 3 & 45 & 0.031 & 0.18 \\
PD $\times$ Age & .89 & .498 & 3 & 45 & 0.686 & 0.03 \\
PD $\times$ Income & .91 & 1.497 & 3 & 45 & 0.228 & 0.09 \\
\hline
\end{tabular}

Note. Psychological Distress=PD; Counselling acceptance $=C A$; Coping style $=C S$

The multivariate tests indicated that the Wilks' Lambda $=0.823, F(3,45)=3.228$, p-value < .05 for depression and anxiety was significant. All other two-way and three-way interactions were not significant. Mauchly's test of sphericity was not assumed ( $p=.001)$, therefore Greenhouse-Geisser $=0.801$ was used as an alternative measure. Greenhouse-Geiser adjustment for sphericity for the association between sociodemographic factors, counseling acceptance, and coping mechanism for psychological distress among victims of domestic violence indicated a significant interaction for Psychological Distress $[F(2.40,144.95)=3.96$, $\mathrm{p}<.05]$. There were no other statistically significant interaction effects.

$H_{a} 1$ : There is a significant difference in sociodemographic factors between domestic violence victims who accepted counseling and those who did not accept counseling at three months follow-up. 
The Chi-Square was calculated to see the differences between the various characteristics and among the group that accepted counseling and the group that didn't accept counseling to determine if there are differences between the two groups in terms of sociodemographic factors; age $\left(X^{2}=30.53, p=.29\right)$, race $\left(X^{2}=3.21, p=.19\right)$, number of children $\left(X^{2}=12.61, p=\right.$ $.05)$, education $\left(X^{2}=0.92, p=.63\right)$. There were no significant differences detected in terms of the respondent's sociodemographic characteristics except for the duration of abuse $\left(X^{2}=\right.$ $28.77, p=.007)$, therefore, Hypothesis 1 was partially supported.

$\mathrm{H}_{a} 2$ : There is a significant difference in coping mechanisms between domestic violence victims who accepted counseling and those who did not accept counseling at three months follow-up. The Chi-square statistic for coping style was $\left(X^{2}=1.51, p=.47\right)$. There was no significant difference between the different coping styles among the respondents. Therefore, this study rejected Hypothesis 2.

$\mathrm{H}_{a} 3$ : There is a significant difference in psychological distress among domestic violence victims who accepted counseling and those who did not accept counseling at baseline and follow-up.

A paired samples t-test was carried out to explore the differences between the symptoms of depression $(r=0.815, p<.05)$ and anxiety $(r=0.712, p<.05)$ at baseline and 3-month follow-up. There was a significant reduction in the respondent's symptoms of anxiety and depression between the baseline and three months of follow-up. Therefore, this study supported Hypothesis 3.

\section{Discussion}

The main findings of this study were that there were no significant differences in terms of their sociodemographic factors except for the duration of abuse but there was a significant reduction in the psychological distress at the baseline and three months follow-up with the respondents from the two groups. This is interpreted as those respondents who accepted counseling and those who did not accept counseling were able to manage their psychological distress through their current coping mechanism which showed a higher preference and utilization of the approach coping mechanism.

This can be concluded that although domestic violence victims can cope with their psychological distress with or without counseling intervention but with counseling, they could probably cope quicker and more efficiently. However, as shown in the findings of this study, only half of the total number of respondents decided to accept counseling. This could be due to various factors such as the shame of being a victim of domestic violence, the stigma of attending counseling sessions, or possibly they are already receiving informal help that works well for them.

In terms of sociodemographic characteristics, only the duration of abuse appeared to be associated with counseling acceptance. This is similar to the findings of Bargai (2007) which states that the duration of exposure to violence links to higher depressive symptoms and learned helplessness mediates the effect of the abuse on the psychological distress that is experienced by the victim.

The majority of the respondents reported that they were experiencing symptoms of depression and anxiety at the baseline. There was a significant reduction for all respondents in symptoms of anxiety and depression after three months. This can be explained with the Learned Helplessness Theory that states that when a person is in a situation that constantly makes them feel helpless and powerless, and can lead to psychological distress. In this case, 
the victims continued to remain in abusive marriages and therefore they continued to experience psychological distress even though some may be more or lesser than others.

Since all the respondents in this study have been in an abusive marriage for one year or more and have been abused more than one time, they may have been abused over and over again and feel that it is finally time to lodge a police report to get some legal action taken against the perpetrator. Having the courage to lodge a police report in itself is an active measure in an attempt to try to help themselves and possibly finding a way to overcome their distress. This action to make a police report may have been suggested by their family members or friends or through online resources since the majority of the victims had an active coping mechanism, thus they would have actively been seeking ways to deal with their abuse and figuring out which would be their best move at that given point in time. However, it should be noted that those who approach coping mechanisms may have been far more likely to report the abuse in the first place.

Street et al. (2005) explained that the experience of being victimized again after prior abuse can create feelings of shame and guilt and reduces the possibility of the victim seeking help. Self-blame falls under the avoidant coping style in the Brief COPE inventory utilized in the current study. This serves as an explanation as to why half of the respondents did not want to receive counseling services as they may have felt that the domestic violence is partly their fault or they may be too embarrassed to talk about their family problems to an outsider. According to Iverson et al. (2013), women who have been abused usually disengage and play a more passive role to help deal with the overwhelming experience of painful emotions and trauma, thus they tend to use an avoidant coping strategy. However, prolonged usage of this type of coping mechanism may increase the risk of mental health issues and psychological distress. Therefore, it is important that counseling is advocated towards this group of women so that they may be able to deal with their mental health more effectively.

A study conducted by Zhukov and Vinogradova (2002) suggested that there was a difference between dominant and subdominant subjects and in terms of their coping styles and managing their mental health. Dominant respondents are those who are usually more dominant in their relationship while the subdominant respondents are those who are less dominant in the relationship. The study found that dominant subjects tend to use active coping styles while subdominant subjects tend to use passive coping styles. This implies that the role of the woman within her family plays a role in how she decides to cope with her issues as well.

Another socioenvironmental factor needs to be considered. Negeri Sembilan is a matriarchal society that abides by the 'adat Perpatih' culture compared to all the other states in Malaysia that follow the 'adat Temenggung' culture which is more patriarchal (Kassim, 1992). Thus, women are given more superiority especially in terms of ancestral properties such as lands, inheritance, and lineage as well as in politics. Taking this factor into account, the role or status that majority of these women may hold within their family may be a more dominant role that is consistent with their coping style as well which is an active style. It could also be because of this 'adat perpatih' that the husbands refuse to divorce the wife because if they do, the husband will end up with no property as the wife will inherit everything. Therefore, the husbands keep the wife as their "financial safe box".

Since Malaysia is a multicultural society, other sociodemographic factors such as ethnicity were a significant predictor where Chinese and Indian women reported a higher rate of domestic violence compared to Malay women, and women who came from lower-income households experienced abuse more than those in higher-income households. This study had 
a higher response rate and included a larger sample size of the various races in Malaysia and included multiple urban primary care clinics compared to the current study that focused only on a smaller sample of respondents and only at one location. However, the current study included other variables such as counseling acceptance and coping mechanisms that were not included in the previous study.

\section{Theoretical Implications}

Based on the findings of the current study, they provide additional support for the theories that were discussed in the earlier chapters. The majority of the victims have been in a cycle of abusive relationships between one to five years, in which the abuse has been happening over a while between one year and up to 25 years for some of them. This finding is also consistent with the Cycle of Violence Theory (Walker, 1979) that explains three main phases that repeat over and over in an abusive relationship over time. It can further be explained by the Learned Helplessness Theory that states that women who have been continuously abused over and over and have tried to get help but to no avail, eventually becomes accustomed to the situation and accept it as part of their life and usually experience some level of psychological distress from it.

Among some of the factors that may contribute towards women feeling helpless and continue to stay in an abusive cycle could be due to their experience in dealing with the legal system in Malaysia or know of someone who may they been in a similar situation and had a bad experience when deciding to leave the abusive relationship. The rate of reports being made and then retracted is rather high in Malaysia in cases involving domestic violence (Adnan, 2019). Interviews with some victims of domestic violence in Malaysia in a study done by Tucker (2012) suggested that the victims who lodged a police report had concerns about the police officers not being cooperative or understanding. Furthermore, as described in the cycle of violence in the honeymoon phase, some of the women felt pitiful for their spouse when they were arrested and withdrew the police report after the husband apologized and made promises that he will change. These women need to understand that once the abuse takes place, it is bound to happen again in a matter of time and awareness should be created in this aspect. Indirectly, when the victims withdraw the police report, hence, the police officer would most likely not take the case too seriously the next time she lodges a report with the expectation that she would retract the report again after all the investigation and arrest work has been done (Tucker, 2012). That would then make the victim feel more helpless especially if at that point of time she was serious about leaving the abusive marriage and felt that she was not getting the help or support needed or even taken seriously. This would then increase her levels of self-blame and guilt which are also symptoms of the Battered Woman Syndrome, making her feel that she deserves to be in that situation.

The cycle of violence doesn't necessarily just stop with the first generation, but it can continue with their children to the next generation and the next through observation and learned behavior (Corbin \& Gonzales, 2010). Thus, it is important to ensure that domestic violence is dealt with as effectively and efficiently as possible so that the cycle ends there and the children can grow up in a healthy and functional environment and the victim can be free from the abuse. By increasing the preventive measures or immediate responses to domestic violence for the victims and the children, it reduces the number of domestic violence cases for the police to deal with in the future, allowing them to focus more in-depth on the other cases that are being reported. 


\section{Practical Implications}

As stated by Bargai (2007), learned helplessness may increase the risk of psychological distress in victims of domestic violence and should be addressed in developing intervention and treatment programs to help reduce the burden of psychological disorders within this population. Understanding the implication of the abusive cycle and learned helplessness on the victim, the services and agencies that offer help to the victims must be sensitive towards these situations and have an insight as to what could be going through the victim's mind and to do what is within their means to ensure that the cycle of violence breaks and that the women gains back her sense of control to do what is best for herself and her family. Campaigns and programs should talk about breaking the cycle and possibly helping the victims to identify if that cycle has been happening within their household and for how long. Such programs can be a collaborative effort between various agencies including the police service, social welfare, educational facilities, medical care as well as other relevant organizations. Even from the school level, school counselors play a role to conduct awareness programs and to identify children who may be showing behavioral or learning problems at school and investigate if any abuse or problems is happening at home and the necessary intervention should be provided to the child and possibly the family too.

Distressing situations could lead to more serious mental health issues and other complex psychological impairments if they are not properly managed. Therefore, it is important for mental health professionals, such as counselors, to assist people who are going through traumatic events such as domestic violence from developing further mental health issues. The field of counseling provides a safe and non-judgemental setting for the victims to get professional help. There are various types of counseling such as family counseling, marital counseling, couple counseling, and others that may be applicable for the victims experiencing different situations. Most of the services offered are free of charge. Since coping styles play an important role in how they cope with their psychological distress, it would be ideal for counselors to equip or explore with the victims the most effective coping skills to help them deal with the psychological distress they may be experiencing.

Understanding the implication of the abusive cycle and learned helplessness on the victim, the services and agencies that offer help to the victims must be sensitive towards these situations and have an insight as to what could be going through the victim's mind and to do what is within the victim's means to ensure that the cycle of violence breaks and that the women gains back her sense of control to do what is best for herself and her family. Campaigns and programs should talk about breaking the cycle and possibly helping the victims to identify if that cycle has been happening within their household and for how long. Such programs can be a collaborative effort between various agencies including the police service, social welfare, educational facilities, medical care as well as other relevant organizations. Even from the school level, school counselors play a role to conduct awareness programs and to identify children who may be showing behavioral or learning problems at school and investigate if any abuse or problems is happening at home and the necessary intervention should be provided to the child and possibly the family too.

Apart from that, in terms of helping the general population of women in this country to not be a victim of domestic violence, would be to empower them from a very young age. Dalal and Lindqvist (2012) explained that education level serves as a protecting factor against women against domestic violence. The government and stakeholders should increase awareness and programs catered towards young girls and women to make them more independent, confident, empowered, and capable. 
Domestic violence is not a personal crime because the impact of the abuse not only affects the victim of the abuse, but also others around them including their children, family members, and friends. Domestic violence can also affect other aspects of the victim's life including their work performance, their social life, physical and mental health, and all of this eventually affects the country's image and economy. Therefore, domestic violence is a public crime and everybody needs to play a role and contribute towards addressing this issue and ensuring the safety and wellbeing of every woman in our society.

\section{Recommendations for Future Research}

Based on the present study, it is recommended that future research includes a larger sample size involving domestic violence victims from the whole of Malaysia to be able to get a more generalizable outcome. Future researchers could study several counseling interventions used for domestic violence victims and evaluate their effectiveness in terms of helping them deal with their psychological distress. Future studies can look into victims if they had past trauma due to other forms of childhood violence to see its effect on how they react to abuse and trauma in their present life. Cultural and other sociodemographic factors can be taken into account in other studies to further investigate the relationship between those factors.

This study mainly focused on women as victims of domestic violence, but according to Ling (2013), men are also victims of domestic violence at times too. However, due to various reasons such as fear of being ridiculed or fear of not being taken seriously, they fail to come forward and this is something that future studies can look into. In general, stereotypes surrounding domestic violence should be further explored and the mindset of society should be changed to be more understanding and accepting towards the victims and provide the necessary support. Many times, domestic violence is a learned behavior and the cycle of abuse needs to be curbed from a young age before it goes from one generation to another. In Malaysia, legally, domestic violence is only viewed under the Domestic Violence Act 1994 if it involves either the husband or wife; ex-husband or ex-wife; children, incapable elders, or other family members. However, most of the other developed countries including the United States define the act of domestic violence as a "felony or misdemeanor crime of violence committed by a current or former spouse or intimate partner of the victim, by a person with whom the victim shares a child in common, by a person who is cohabitating with or has cohabitated with the victim as a spouse or intimate partner, by a person similarly situated to a spouse of the victim under the domestic or family violence laws of the jurisdiction receiving grant monies, or by any other person against an adult or youth victim who is protected from that person's acts under the domestic or family violence laws of the jurisdiction (US Department of Justice, 2020). This is also something that can further be studied especially by the policymakers because domestic violence does not only happen within the marriage but also between romantic partners, those who cohabitate, and even within the LGBT community. In summary, future research may want to have a larger sample and study more variables such as religion, cultural aspects, and the effect of domestic violence on children to have more insight into the victim's worldview and attitudes towards counseling acceptance, which can be achieved by increasing awareness and promotion of services.

There is also a need to further explore the effect of domestic violence on not only women but men as well and to understand why men may not be coming forward to seek help or take legal action against their spouses. Besides that, it is also recommended that the laws and policies in regards to domestic violence are re-evaluated and to make any necessary changes that may be more relevant to victims of domestic violence in Malaysia during recent times. 


\section{Conclusion}

This study offers insight into counseling acceptance rates and their psychological correlates among domestic violence victims from a single victim care center. Findings can help increase understanding of victims' coping mechanisms and associated psychological distress which can be targeted to increase counseling acceptance rates.

\section{References}

Adnan, A. S. (2019). Mangsa keganasan rumah tangga perlu kumpul bukti, lapor polis, Berita Harian. https://www.bharian.com.my/berita/nasional/2019/11/625004/mangsa-keganasanrumah-tangga-perlu-kumpul-bukti-lapor-polis

Akta Keganasan Rumah Tangga (1994). Tafsiran. Retrieved on November 10, 2019, from:http://www.wao.org.my/backup_v1_21.7.2011/Documents/AKTA_KEGANASA N_RUMAH_TANGGA_1994.pdf

Bargai, N., Ben-Shakhar, G., \& Shalev, A. (2007). Posttraumatic Stress Disorder and Depression in Battered Women: The Mediating Role of Learned Helplessness. Journal of Family Violence, 22(5), 267-275.

Bathke, A., Schabenberger, O., Tobias, R., and Madden, L. (2009). GreenhouseGeisser adjustment and the ANOVA-Type statistic: Cousins or twins? The American Statistician, 63(3): 239-246.

Beck, A. T., Ward, C. H., Mendelson, M., Mock, J., and Erbaugh, J. (1961). An inventory for measuring depression. Archives of General Psychiatry, 4: 561-571.

Beck, A. T., Epstein, N., Brown, G., and Steer, R. A. (1988). An inventory for measuring clinical anxiety: Psychometric properties, Journal of Consulting and Clinical Psychology, 56 (6): 893-897.

Brabeck, K., and Guzman, M. (2008). Frequency and perceived effectiveness of strategies to survive abuse employed by battered Mexican origin women. Violence Against Women, 14: 1274-1294.

Carver, C. (2013). Coping. In: Gellman M.D., Turner J.R. (eds) Encyclopedia of Behavioral Medicine. Springer, New York, NY

Corbin, J., and Gonzales, R. (2010). The Cycle of Violence: Domestic Violence and Its Effects on Children. Retrieved January 15, 2020 from: https://core.ac.uk/download/pdf/47210066.pdf

Crossman, A. (2020). Understanding Purposive Sampling: An Overview of the Method and Its Applications. Retrieved February 18, 2020, from: https://www.thoughtco.com/purposive-sampling-3026727

Dalal, K., and Lindqvist, K. (2012). A national study of the prevalence and correlates of domestic violence among women in India. Asia Pacific Journal of Public Health, 24(2): 265-277.

Fraenkel, J. R., Wallen, N. E., \& Hyun, H. H. (2012). How to deslgn and evaluate research In educatlon (8th ed.). New York: Mc Graw Hill.

Ghani, M. A. (2018). The impacts of domestic violence on children: Perspectives from women in Malaysia who experience abuse. Child Welfare 96(3): 103-117.

Irving, L., and Liu, B. C. (2020). Beaten into submissiveness? An investigation into the protective strategies used by victims of domestic abuse. Journal of interpersonal violence, 35(1-2): 294-318. 
Iverson, K. M., Litwack, S. D., Pineles, S. L., Suvak, M. K., Vaughn, R. A., \& Resick, P. A. (2013). Predictors of intimate partner violence revictimization: The relative impact of distinct PTSD symptoms, dissociation, and coping strategies. Journal of Traumatic Stress, 26(1): 102-110.

Kassim, A. (1992) Women in the matrilineal adat perpatih society in Malaysia:

Continuity and change, Indonesia circle. School of Oriental \& African Studies. Newsletter, 20:57, 3-14.

Ling, M. C. (2013). Experience of leaving an abusive relationship among women survivors. Ph.D. thesis, University of Malaya.

National Institute of Mental Health. (2020). Post Traumatic Stress Disorder.

Retrieved February 20, 2020, from: https://www.nimh.nih.gov/health/topics/posttraumatic-stress-disorder-ptsd/index.shtml

Oon, W., Shuib, R., Ali, S., Endut, N., Osman, I., Abdullah, S., \& Ghani, P. (2016).

Exploring the coping mechanism of women experiencing intimate partner violence in Malaysia. International E-journal of Advances in Social Sciences. 2: 549.

Othman, S., \& Essau, A. C. (2019). Adolescent health risk behaviors and mental health: evidence from the Malaysian national health and morbidity survey 2017. Asia Pacific Journal of Public Health, 31(8): 65-75.

Overmier, J. B., and Seligman, M. E. (1967). Effects of inescapable shock upon Subsequent escape and avoidance responding, J Comp Physiol Psychol., 63(1): 28-33.

Rahman, A. A., Mahdzir, N., Thalbi, C., and Rahim, A. (2019). Combating domestic violence in Malaysia: issues and challenges. Retrieved February 15, 2020, from: https://www.researchgate.net/profile/Aspalella-ARahman/publication/330383422_Combating_Domestic_Violence_in_Malaysia_Issue s_and_Challenges/links/5c3d5cb292851c22a375cd1e/Combating-DomesticViolence-in-Malaysia-Issues-and-Challenges.pdf

Seligman, M. E. P., and Beagley, G. (1975). Learned helplessness in the rat. Journal of Comparative and Physiological Psychology, 88: 534-541.

Street, A. E., Gibson, L. E., and Holohan, D. R. (2005). Impact of childhood traumatic events, trauma-related guilt, and avoidant coping strategies on PTSD symptoms in female victims of domestic violence. Journal of Traumatic Stress, 18(3): 245-252.

Tucker, A. (2012). The Malaysian Police and Domestic Violence. Retrieved February 19, 2020, from: https://ujslcbr.org/index.php/ujslcbr/article/download/147/127

US Department of Justice. (2020) Domestic Violence. Retrieved October 19, 2020, from: https://www.justice.gov/ovw/domestic-violence

Walker, L. E. (1979). The Battered Woman.[Infographic]. Retrieved March 20, 2020, from: http://www.1736familycrisiscenter.org/

Walker, L. E. (1979). The Battered Woman. New York: Harper and Row.

Women's Aid Organization (2011). Introduction. Retrieved July 29, 2020, from: http://www.wao.org.my/Introduction_139_139_1.htm

Women's Aid Organization (2017). A Coordinated Community Response to a Community Issue. Retrieved September 10, 2020, from: https://wao.org.my/wpcontent/uploads/2018/08/Perspectives-on-

Domestic-Violence.pdf

World Health Organisation (2021). Violence Against Women. Retrieved January 26, 
INTERNATIONAL JOURNAL OF ACADEMIC RESEARCH IN BUSINESS AND SOCIAL SCIENCES

Vol. 11, No. 8, 2021, E-ISSN: 2222-6990 @ 2021 HRMARS

2021, from: http://www.who.int/mediacentre/factsheets/fs239/en/

Zhukov, D. A., and Vinogradova, K. P. (2002). Learned helplessness or

learned inactivity after inescapable stress? Interpretation depends on coping styles.

Integrative Physiological \& Behavioural Science 37: 35-43. 